\title{
Decoding Complexity in Structure-Sensitive Reactions
}

Toyin Omojola*

Department of Chemical Engineering. University of Bath. Bath. BA2 7AY. UK

\section{*toyin.omojola@cantab.net}

\begin{abstract}
Structure-sensitive reactions involving the Mars and van Krevelen mechanism over metal and metal oxide catalysts are ubiquitous in reaction kinetics and engineering. The kinetic equations of such reactions are re-written to account for modern operando spectroscopy and microscopy observations. Emphasis is placed on reactions with nucleophilic (lattice) oxygen, oxygen reduction reversibility, an interconversion scheme, non-linear water adsorption, remote-control model, and non-uniform sites. The multiplicity of propane conversion over MoVTeNbOx catalysts is proven through a combination of non-linear competitive water adsorption, presence of multiple active sites, a re-structuring active site, and oxygen adsorption. The modified remote-control kinetics for the Mars and van Krevelen mechanism can account for the observations of steady-state multiplicities and hysteresis. The results have implications for improving catalytic activity, reducing operating process costs, and active site engineering of selective oxidation catalysis.
\end{abstract}

Keywords: Classical kinetics, Mars and van Krevelen mechanism, hysteresis loops, steady-state multiplicity, reaction engineering, active site engineering 


\section{Introduction}

The Mars and van Krevelen rate expression ${ }^{1}$ that explains a surface redox mechanism has been used to describe rates of oxidation reactions over metals and oxides for over 65 years. There was, however, limited mechanistic understanding of the coupling of chemical dynamics and solid-state kinetics for regulation of the performance (activity, selectivity, and stability) of heterogeneously catalysed reactions. Limited or no operando spectroscopic and microscopic evidence was obtained for the dynamics of this mechanism in the 1950s. Consequently, there are limited attempts to produce a realistic kinetic expression of this mechanism.

About 15 years ago, Vannice ${ }^{2}$ noticed this problem and attempted to produce a realistic model of the initial reaction studied by Mars and van Krevelen. Vannice reinvestigated the kinetics involved in the oxidation of benzene to benzoquinone, maleic anhydride, carbon dioxide, carbon monoxide and water as well as toluene to benzaldehyde and benzoic acid, naphthalene to naphthoquinone and phthalic anhydride. Inconsistencies in the Mars and van-Krevelen rate expression were highlighted due to specification of which oxygen adspecies are involved in the reaction, lumped kinetic steps and a lack of input of competitive adsorption of the involved intermediate species or final products. Having highlighted these inconsistencies, adequate kinetic rate expressions were produced for situations including a HougenWatson model where the product desorption is the rate determining step, and the addition of molecular or dissociation $\mathrm{O}$ species and conditions when a LangmuirHinshelwood rate expression is more realistic to depict occurrences where the rate determining step is an elementary step occurring on the surface, while all other steps are quasi-equilibrated. Vannice ${ }^{2}$ concluded that although the Mars and van Krevelen 
mechanism can adequately describe most oxidation reactions, its kinetics has "no physical relevance" and must be viewed only as a mathematical fitting function.

Catalytic activity and product selectivity during oxidation catalysis depends greatly on the morphology, composition and oxidation state of the catalyst. ${ }^{3,4}$ As particle morphology changes, hysteresis loops or steady-state multiplicities may occur. Multiplicity of steady-state has been observed during the oxidation of ethene on platinum catalysts. ${ }^{5}$ Multiplicity of steady-state means that different values of the reaction rate correspond to the same composition of the reaction mixture or to the same temperature i.e., various steady-state reaction rates corresponds to singular values of rate constants. ${ }^{6}$ Multiplicity of steady-state is usually accompanied by hysteresis. ${ }^{7}$ Multiplicity of steady-states has been found for the oxidation of hydrogen over nickel catalysts ${ }^{8,9}$, the oxidation of carbon monoxide over platinum-group metals both at atmospheric and under high-vacuum conditions ${ }^{10,11}$, the hydrogenation of carbon monoxide over $\mathrm{Ni}^{-\mathrm{Al}^{12}}$, the oxidation of ammonia ${ }^{13}$, and sulphur dioxide over platinum ${ }^{14}$, and the reaction of nitrous oxide with carbon monoxide over platinum. ${ }^{15}$

In order to decipher this complex phenomena, various suggestions have been made, including the interaction between adspecies via competitive adsorption as well as the reversible change in the number of active sites, variation in the rate coefficients under the influence of changes in surface coverages or subsurface concentrations, adsorption-induced desorption due to superheating at local points on the catalyst surface, branching chain processes on the catalyst surface, phase transformation at the catalyst surface, interaction between kinetic and diffusional processes (in this case, interaction between kinetics and surface diffusion processes lead to selfsustaining waves or self-organising processes) and the effects of heat and mass transfer processes. ${ }^{7}$ 
Kinetic instabilities can occur in a number of surface reactions on transition metals involving oxygen, ${ }^{16-20}$ but it is still unsettled as to how these instabilities should be described in terms of a kinetic model. Eigenberger studied kinetic instabilities in heterogeneous catalysed reactions with Langmuir-type kinetics ${ }^{6,21}$ as well as the dynamic behaviour of the catalytic fixed-bed reactor in the region of multiple steadystates. $^{22,}{ }^{23}$ Eigenberger considered the conditions under which steady-state rate multiplicity (ignition-extinction phenomena) occurs for a general reaction of $\mathrm{pA}+\mathrm{qB} \leftrightarrow$ C. They showed that rate multiplicity is generally linked to the competing chemisorption of $A$ and $B$ on the same active sites and does not occur for an EleyRideal type mechanism. This general scheme produced a triangular site dependency which was used to describe rate multiplicities occurring over platinum if isothermality occurs and mass transfer limitations are excluded. Product desorption has no considerable influence. An excess in pellet temperature in the case of an exothermic reaction and internal pore diffusion leads to increase in hysteresis between ignition and extinction. ${ }^{24}$ Competitive adsorption between the two reactants in the general model as well as the secondary role played by the product specie leads to the assumption that the reactants are responsible for the occurrence of observed oscillations, while the third component is in equilibrium or in quasi-steady state. This assumption ${ }^{21}$ reduces the kinetic model to a second order system and allows the application of the Bendixon-Dulac ${ }^{25}$ criterion to study whether oscillations can occur or not. In the general scheme above, although rate multiplicities are observed, no description of oscillatory instabilities were obtained. Nonetheless, it was observed that a periodic succession of ignited and extinguished states can develop if a slow chemisorption step, which acts as a buffer or storage for provision of empty sites after the reaction is extinguished and which consumes empty sites after an ignition has 
taken place. This latter model was successfully used to describe oscillations of carbon monoxide oxidation on platinum in a loop reactor. ${ }^{21}$

Recently, Rupprechter and co-workers ${ }^{26,27}$ reported the direct observation of multi-frequential oscillations occurring during the hydrogen oxidation reaction over a heterogeneous rhodium surface composed of $\mu \mathrm{m}$-sized domains of different crystallographic orientations. Photoemission electron microscopy studies in combination with microkinetic modelling ${ }^{27}$ reveal that each particular domain exhibits its own local oscillation frequency which appears to be governed by the local rhodium surface structure, with structure-sensitive subsurface oxygen formation serving as feedback mechanism. Moreover, using high spatially and temporally resolved in situ field electron microscopy studies ${ }^{26}$ of oscillatory hydrogen oxidation over rhodium, various forms of spatial coupling was observed. These include interfacet coupling, entrainment, frequency locking, and reconstruction-induced collapse.

On the reactor-scale, multiple steady-states can exist. ${ }^{22,23}$ Eigenberger showed that multiple steady-states occur due to heat conduction which flows in the opposite direction to fluid flow (this reactor dynamic is observed through the change in catalyst temperature), and also from the fact (described above) that reaction takes places on the surface and/or inside the catalyst pellet. The latter results in differentiable temperature and concentration profiles in the pellet, despite unchanging conditions in the surrounding gas phase. Catalyst behaviour in the region of multiple-steady-states is essentially affected by the boundary conditions of the catalyst phase. The ubiquitous two-fold stable steady-state exists only if the fixed-bed is composed of three parts; the first and the third parts consists of inert material and the second contains the active catalyst. There are, however, limited studies that link multiplicity of steady-state on the catalyst grain-scale to the multiplicities observed on the reactor scale. 
Previous work on steady-state multiplicities using the "classical kinetic" approach generally investigate carbon monoxide oxidation on platinum through a general scheme. A lot of work has focused on the kinetic factors such as the influence of competitive adsorption, product desorption, and transport limitations such as conduction and convection in an opposite direction to fluid flow. The novelty in this work is that we incorporate observations from operando microscopy and spectroscopy studies, which were not available in the 1970s and the 1980s when factors leading to instabilities were investigated. There exist limited investigations that incorporate the effect of recent state-of-the-art operando spectroscopy and microscopy observations, which affirm the Mars and van Krevelen mechanism that is prevalent in oxidation catalysis.

In order to determine the relevant rate expressions, the following descriptors are incorporated: the inclusion of lattice oxygen, the reversibility of the oxygen reduction mechanism, ${ }^{28}$ non-uniform and restructured surfaces due to adsorptioninduced dynamical changes, ${ }^{29}$ an interconversion model involving hydrocarbon oxidation with two metal-oxygen species of different nature effected by strain effects in catalysis, and a remote control model ${ }^{30}$ on the regulation of active sites using partial pressures of educts. Archived studies were mainly conducted for carbon monoxide oxidation over metal catalysts or for reactions where selectivity issues were not prominent. This work is novel in this additional aspect as we address phenomena relating to rate analysis (section 2.5 ) and link this directly to coverage-dependent multiplicity effects (section 3.6).

Furthermore, of the various reasons for multiplicity and hysteresis, emphasis is placed on coverage-dependent steady-state rate multiplicities in which a single rate coefficient leads to multiple rates. The role of the variation in the rate coefficients under 
the influence of changes in surface coverages in determining the presence of steadystate multiplicities and the ensuing hysteresis is investigated.

The theoretical proofs are compared to recent experimental results of the partial oxidation of propane over the meta-stable MoVTeNbOx catalysts published in refs. ${ }^{31}$, ${ }^{32}$ For the first time, we show that steady-state multiplicities occur when a redox site and a restructured site is involved, as well as non-linearity in the chemical process due to steam adsorption occurs. Such cases explain the recent hysteresis observed in alkane oxidation over mixed metal oxide catalysts and increased acrylic acid selectivity due to tellurium enrichment. ${ }^{31,32}$ Steady-state multiplicities allow for improvement in catalyst performance, process operation at lower stringent operating conditions and has huge cost implications for the industrial selective oxidation process. 


\section{Mars and van Krevelen Mechanism}

The first set of kinetic studies conducted for selective oxidation was based on the Mars and van Krevelen mechanism. ${ }^{1}$ Mars and van Krevelen highlighted two pathways leading from aromatic oxidation to oxidation products. The original paper stated that:

1. Aromatic compound + oxidized catalyst $\rightarrow$ oxidation products + reduced catalyst

2. Reduced catalyst + oxygen $\rightarrow$ oxidized catalyst

Following these statements, the following rate equations were written:

$n_{R}=k_{1} P_{R} \theta$

$n_{O 2}=k_{2} P_{O 2}^{n}(1-\theta)$

Then a statement was made that if "for the oxidation of one aromatic molecule, $\beta$ molecules of oxygen are required", then the following formula holds:

$n_{R}=\frac{n_{O 2}}{\beta}$

$\beta k_{1} P_{R} \theta=k_{2} P_{O 2}^{n}(1-\theta)$

$\theta=\frac{k_{2} P_{O 2}^{n}}{\beta k_{1} P_{R}+k_{2} P_{O 2}^{n}}$

$n_{R}=\frac{k_{1} k_{2} P_{O 2}^{n} P_{R}}{\beta k_{1} P_{R}+k_{2} P_{O 2}^{n}}$

Then for $\beta=1$, and $n=1$,

$$
n_{R}=\frac{k_{1} k_{2} P_{O 2} P_{R}}{k_{1} P_{R}+k_{2} P_{O 2}}
$$


The assumption of $\beta=1$ shows that Mars and van Krevelen" imply that "for the oxidation of one aromatic molecule, one molecule of oxygen is required". Consequently, we can write the stoichiometry that Mars and van Krevelen ${ }^{1}$ used in the derivation of their equations:

1. $R+S-O_{2} \rightarrow R-O_{2}+S$

2. $\mathrm{S}+\mathrm{O}_{2} \rightarrow \mathrm{S}-\mathrm{O}_{2}$

$R$ is a reactant molecule, and $S$ is an active site. Clearly, the Mars and van Krevelen rate expression did not consider the reduction of molecular oxygen to lattice oxygen. Recent investigations ${ }^{28}$ show that the Mars van Krevelen rate expression ${ }^{1}$ does not include nuanced descriptions of selective oxidation such as re-structuring, competitive adsorption (no adsorbed products) and reactions with other forms of adsorbed species. A modification of the kinetics of the Mars and van Krevelen equation is necessary and provided in five possible ways that incorporate recent stateof-the-art operando spectroscopic and microscopic experimental findings.

\subsection{Inclusion of lattice oxygen}

It is widely assumed that oxygen, upon adsorption on the catalyst surface can accept electrons in a step-by-step manner until its transformation into its fully reduced form. Oxygen species are distributed spatially and temporally on the catalyst surface in their adsorbed form, electrophilic forms, and nucleophilic forms. Oxygen species differ in charge, coordination, and bond energy. The subject of many studies is the investigation of the key oxygen specie under catalytic conditions and which of these oxygen species governs selectivity. ${ }^{28}$ Generally, it is widely believed that in most partial oxidation reactions, nucleophilic (lattice) oxygen species are responsible for selective 
oxidation, while electrophilic oxygen species (superoxides, peroxides, charged oxygen ion, adsorbed molecular oxygen) are responsible for complete oxidation. In the scheme below, emphasis is based on reaction between the educt and lattice oxygen.

1. $R+S-O \rightarrow R-O+S$

2.S $+0.5 \mathrm{O}_{2} \rightarrow S-O$

$n_{R}=\frac{k_{1} k_{2} P_{O 2} P_{R}}{0.5 k_{1} P_{R}+k_{2} P_{O 2}}$

However reactions with half a molecule of oxygen ${ }^{33}$ are unlikely, thus further modifications are required. $k_{1}$ represent rate constants for the forward step " $i$ ". Po2 is the partial pressure of oxygen, $P_{R}$ is the partial pressure of the reactant gas.

\subsection{Reversibility of the oxygen reduction mechanism}

The first step in the incorporation of molecular oxygen is a reversible oxygen adsorption step. Consequently, dissociation occurs leading to other $\mathrm{O}$ species. ${ }^{34}$ Over vanadium pyrophosphate catalysts, the reversibility of the oxygen exchange within one redox cycle is demonstrated. ${ }^{35}$

1. $R+O-S \rightarrow R-O+S$ (RDS)

2.S $+\mathrm{O}_{2} \rightleftharpoons \mathrm{SO}_{2}$

3. $\mathrm{SO}_{2}+\mathrm{S} \rightleftharpoons 2 \mathrm{SO}$

RDS represents the rate-determining step. The rate of reaction is dependent on the first order of propane and a complex order with respect to oxygen, as observed by ref 36

$n_{R}=\frac{k_{1} P_{R} K_{S O}^{0.5} K_{S O 2}^{0.5} P_{O 2}^{0.5}}{1+K_{S O 2} P_{O 2}+K_{S O}^{0.5} K_{S O 2}^{0.5} P_{O 2}^{0.5}}=\frac{\left(k_{1} K_{S O}^{0.5} K_{S O 2}^{0.5}\right) P_{R} P_{O 2}^{0.5}}{1+K_{S O 2} P_{O 2}+K_{S O}^{0.5} K_{S O 2}^{0.5} P_{O 2}^{0.5}}$ 
KsO2 can be provided by adsorption calorimetry and a variation of $\mathrm{P}_{\mathrm{R}}$ and $\mathrm{P}_{\mathrm{O} 2}$ with $\mathrm{n}_{\mathrm{R}}$ could be used to extract $k_{1}$ and Kso. However, the aforementioned equation does not account for product adsorption or competitive adsorption which has been observed between acrylic acid and steam. No active site dynamics were accounted for. Kso2 is the adsorption constant for oxygen on site "s". Kso is the adsorption constant of $\mathrm{O}$ specie on site "s". Vannice ${ }^{2}$ obtained further rate expressions allowing for product desorption (following the Hougen-Watson methodology) as the rate determining step.

\subsection{Non-uniform and re-structured active sites}

Clean and modified surfaces have widely been demonstrated during oxidation catalysis either on single films or on real industrial catalysts. ${ }^{4}$ Adsorption-induced reconstructions, and restructuring have also been demonstrated. ${ }^{3,37}$ During oxidation catalysis, overlayer formation and restructuring occurs. ${ }^{29}$ The following scheme may be tenable:

1. $R+O-S_{1} \rightarrow R-O+S_{1}$

2. $R+O-S_{2} \rightarrow R-O+S_{2}$

3. $S_{1}+O_{2} \rightleftharpoons S_{1} O_{2}$

4. $S_{1} O_{2}+S_{1} \rightleftharpoons 2 O-S_{1}$

5. $O-S_{1} \rightleftharpoons O-S_{2} \quad$ (restructuring)

$S_{1}$ is site 1 and $S_{2}$ is site 2 . We obtain after subsequent analysis (with RDS of alkane oxidation on both sites) giving:

$n_{R}=\frac{\left(k_{1} K_{O-S 1}^{0.5} K_{O 2-S 1}^{0.5}+k_{2} K_{O-S 2} K_{O-S 1}^{0.5} K_{O 2-S 1}^{0.5}\right) P_{R} P_{O 2}^{0.5}}{1+K_{O-S 2} K_{o-S 1}^{0.5} K_{O 2-S 1}^{0.5} P_{O 2}^{0.5}+K_{O-S 1}^{0.5} K_{O 2-S 1}^{0.5} P_{O 2}^{0.5}+K_{O 2-S 1} P_{O 2}}$ 
This equation still gives a first order with respect to propane and complex order with respect to oxygen as observed by ref. ${ }^{36}$ We do note that in the aforementioned analysis, several parameters are to be determined from only modulating $\mathrm{n}_{\mathrm{R}}, \mathrm{P}_{\mathrm{R}}$ and Po2. The inverse methodology proposed by Froment and Bischoff could be used. ${ }^{38}$ 


\subsection{Interconversion model}

An interconversion model is largely used to explain a changing number of sites or ratios of sites during oxidation catalysis. ${ }^{39}$ This is largely important since the bulk oxide catalyst can serve as a reservoir for generation of active sites on the catalyst surface. The following scheme is tenable:

1. $R+O-S_{1} \rightarrow R-O+S_{1}$

2. $R+O-S_{2} \rightarrow R-O+S_{2}$

3. $S_{1}+O_{2} \rightleftharpoons S_{1} O_{2}$

4. $S_{1} O_{2}+S_{1} \rightleftharpoons 2 O-S_{1}$

5. $\mathrm{S}_{2}+\mathrm{O}_{2} \rightleftharpoons \mathrm{S}_{2} \mathrm{O}_{2}$

6. $S_{2} \mathrm{O}_{2}+S_{2} \rightleftharpoons 2 O-S_{2}$

7. $\mathrm{O}-\mathrm{S}_{2}+\mathrm{O}-\mathrm{S}_{1}+\mathrm{H}_{2} \mathrm{O} \rightleftharpoons \mathrm{H}_{2} \mathrm{O}-\mathrm{S}_{2}+\mathrm{O}_{2}+S_{1}$

From 3: $\theta_{O 2-S_{1}}=K_{3} P_{O 2} \theta_{S 1}$

From 4: $\theta_{O-S_{1}}=\left(K_{4} \theta_{S 1} \theta_{O 2-S_{1}}\right)^{1 / 2}=\left(K_{4} K_{3} P_{O 2}\right)^{1 / 2} \theta_{S 1}$

From 5: $\theta_{O 2-S_{2}}=K_{5} P_{O 2} \theta_{S 2}$

From 6: $\theta_{O-S_{2}}=\left(K_{6} \theta_{S 2} \theta_{O 2-S_{2}}\right)^{1 / 2}=\left(K_{6} K_{5} P_{O 2}\right)^{1 / 2} \theta_{S 2}$

From 7: $\theta_{H 2 O-S 2}=\frac{K_{7} \theta_{O-S 2} \theta_{O-S 1}}{\theta_{S 1}} \frac{P_{H 2 O}}{P_{O 2}}$

For non-competitive adsorption, site balance over site 1 is given as:

$\theta_{S 1}+\left(K_{4} K_{3} P_{O 2}\right)^{1 / 2} \theta_{S 1}+K_{3} P_{O 2} \theta_{S 1}=1$ 
$\theta_{S 1}=\frac{1}{1+\left(K_{4} K_{3} P_{O 2}\right)^{1 / 2}+K_{3} P_{O 2}}$

Over site 2, we obtain:

$\theta_{S 2}+\left(K_{6} K_{5} P_{O 2}\right)^{1 / 2} \theta_{S 2}+K_{5} P_{O 2} \theta_{S 2}+\frac{K_{7} \theta_{O-S 2} \theta_{O-S 1}}{\theta_{S 1}} \frac{P_{H 2 O}}{P_{O 2}}=1$

$\frac{K_{7} \theta_{O-S 2} \theta_{O-S 1}}{\theta_{S 1}} \frac{P_{H 2 O}}{P_{O 2}}=K_{7}\left(K_{4} K_{3} P_{O 2}\right)^{1 / 2} K_{5} P_{O 2} \theta_{S 2} \frac{P_{H 2 O}}{P_{O 2}}=1$

$\theta_{S 2}=\frac{1}{1+\left(K_{6} K_{5} P_{O 2}\right)^{1 / 2}+K_{5} P_{O 2}+K_{7}\left(K_{4} K_{3} P_{O 2}\right)^{1 / 2} K_{5} P_{H 2 O}}$

Thus, rate of reaction over site 1 is given as:

$n_{R}=k_{1} P_{R}\left(K_{4} K_{3} P_{O 2}\right)^{1 / 2} \theta_{S 1}=\frac{k_{1} P_{R}\left(K_{4} K_{3} P_{O 2}\right)^{1 / 2}}{1+\left(K_{4} K_{3} P_{O 2}\right)^{1 / 2}+K_{3} P_{O 2}}$

And over site 2, it is given as:

$n_{R}=k_{2} P_{R}\left(K_{6} K_{5} P_{O 2}\right)^{1 / 2} \theta_{S 2}=\frac{k_{2} P_{R}\left(K_{6} K_{5} P_{O 2}\right)^{1 / 2}}{1+\left(K_{6} K_{5} P_{O 2}\right)^{1 / 2}+K_{5} P_{O 2}+K_{7}\left(K_{4} K_{3} P_{O 2}\right)^{1 / 2} K_{5} P_{H 2 O}}$

\subsection{Remote-control model}

During oxidation catalysis over MoVTeNbOx catalysts, the catalyst surface can be depicted as having (1) primary redox component represented by Vanadium (2) a secondary hydroxyl component, which can only be formed as a result of the primary redox cation and (3) primary re-structuring site (Figure 1). At an initial stage, only the redox and hydroxyl groups are present. High selectivity of acrylic acid in the presence of steam during the partial oxidation of propane over MoVTeNbOx catalysts has been attributed to the formation of mobile Te-containing clusters through the hydrolysis of oligomeric $(\mathrm{TeO})_{n}$ species in the channels of the $\mathrm{M} 1$ structure, which migrate to the surface. Enhanced volatility of $\mathrm{TeO}_{2}$ in water vapor has been attributed to the formation 
of gaseous $\mathrm{TeO}(\mathrm{OH})_{2} .{ }^{40,41}$ This mechanism for surface enrichment of tellurium was earlier proposed by Glemser et al. ${ }^{42,43}$ However, the kinetics of this mechanism has not been critically evaluated. The mechanism of re-structuring, due to adsorption of educts, intermediates, and products, varies between selective oxidation catalysts. For the determination of steady-state multiplicity, the mechanism of Glemser and coworkers ${ }^{42,43}$ was examined in section 3.5. It was observed that the presence of a linear reaction step breaks the coverage-dependent multiplicity function. However, the mechanism was re-modified in section 3.6 to remove all linear steps, albeit the surface enrichment of tellurium. The new mechanism is presented in Figure 1.

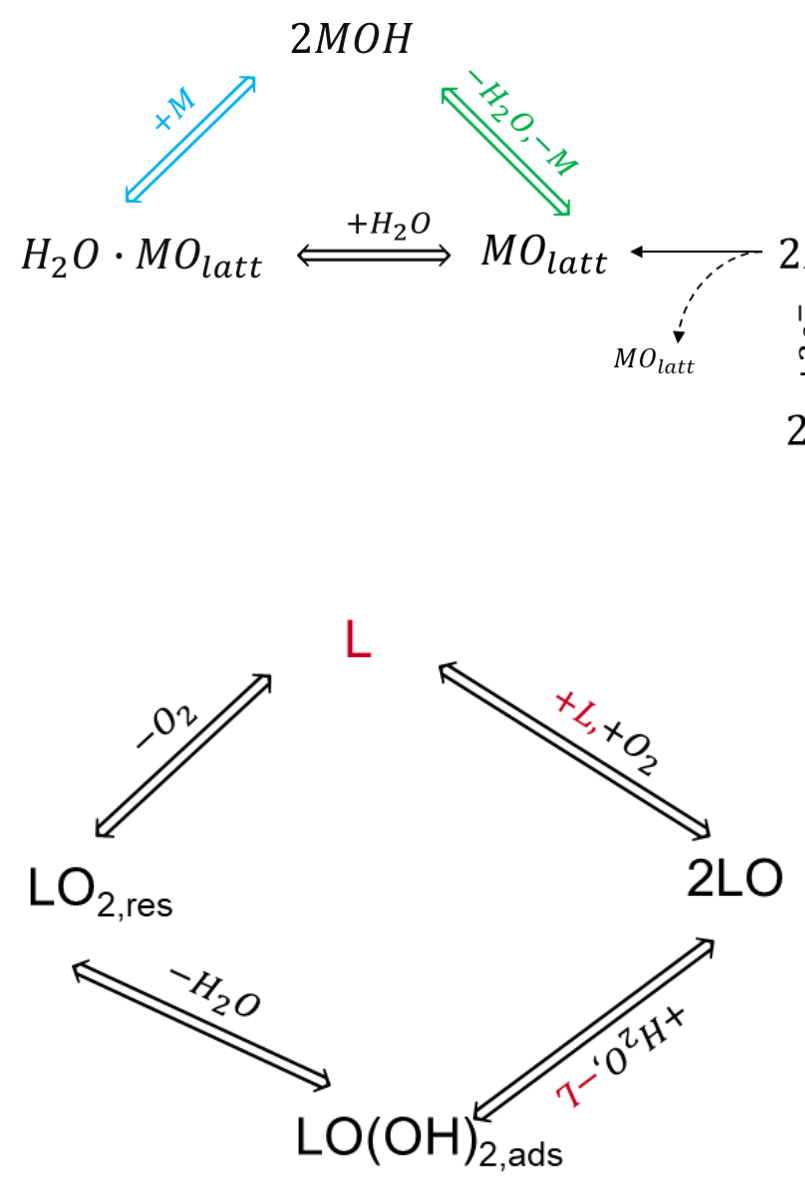

Figure 1: A pictorial description of primary (redox, and re-structuring functions) and secondary (hydroxyl) active sites during oxidation catalysis over mixed metal oxide catalysts. Here, for MoVTeNbOx, M represents Vanadium, L represents Tellurium 
The quantity of active sites can be regulated through the presence of oxygen and steam (Figure 1). The interconversion reaction is given by:

$\mathrm{O}-\mathrm{S}_{1}+\mathrm{H}_{2} \mathrm{O} \rightleftharpoons \mathrm{O}-\mathrm{S}_{2}+\mathrm{O}_{2}$

Following the methodology of Froment et al. ${ }^{39,44-47}$, we obtain:

$\frac{P_{O 2}}{P_{H 2 O}}=K_{4} \frac{\theta_{O-S_{1}}}{\theta_{O-S_{2}}}$

$$
\theta_{O-S_{2}}=K_{4} \theta_{O-S_{1}} \frac{P_{H 2 O}}{P_{O 2}}
$$

The following scheme in this remote-control mechanism is given as:

1. $S_{1}+O_{2} \rightleftharpoons S_{1} O_{2}$

2. $S_{1} O_{2}+S_{1} \rightleftharpoons 2 O-S_{1}$

3. $R+O-S_{1} \rightarrow I-O+S_{1}$

4. $O-S_{1}+H_{2} O \rightleftharpoons O-S_{2}+O_{2}$

5. $O-S_{2}+I-O \rightarrow P-O+O-S_{2}$

An intermediate requires the one site, namely $\mathrm{O}-S_{1}$, then the remote-control mechanism operates, and the generated site formed as a result of remote control is used to convert the intermediates to products.

$\theta_{O 2-S 1}=K_{1} P_{O 2} \theta_{S 1} ; \theta_{O-S 1}=\left(K_{2} \theta_{O 2-S 1} \theta_{S 1}\right)^{1 / 2}$

Site balance gives:

$$
\begin{aligned}
& \theta_{S 1}+\theta_{O 2-S 1}+\theta_{O-S 1}=1 \\
& \theta_{S 1}+K_{1} P_{O 2} \theta_{S 1}+\left(K_{2} K_{1} P_{O 2}\right)^{1 / 2} \theta_{S 1}=1 \\
& n_{I-O}=\frac{k_{3} P_{R}\left(K_{2} K_{1} P_{O 2}\right)^{1 / 2}}{1+K_{1} P_{O 2}+\left(K_{2} K_{1} P_{O 2}\right)^{1 / 2}}
\end{aligned}
$$


On site 2, the product is formed and subsequently,

We know from the remote-control model that:

$\theta_{O-S_{2}}=K_{4} \theta_{O-S_{1}} \frac{P_{H 2 O}}{P_{O 2}}$

Thus, rate of product formation is given as:

$n_{P-O}=k_{5} P_{I-O} \theta_{O-S 2}=k_{5} K_{4} P_{I-O} \theta_{O-S_{1}} \frac{P_{H 2 O}}{P_{O 2}}=k_{5} K_{4} P_{I-O}\left(K_{2} K_{1} P_{O 2}\right)^{1 / 2} \theta_{S 1} \frac{P_{H 2 O}}{P_{O 2}}$

$n_{P-O}=\frac{k_{5} K_{4} P_{I-O}\left(K_{2} K_{1} P_{O 2}\right)^{1 / 2} \frac{P_{H 2 O}}{P_{O 2}}}{1+K_{1} P_{O 2}+\left(K_{2} K_{1} P_{O 2}\right)^{1 / 2}}$

Figure 1 is a schematic for understanding how the site distribution on an "active surface" of a MoVTeNbOx catalyst can be tuned to produce the required acrylic acid selectivity from propane. This schematic assumes that electron transfer is concurrent with oxygen adsorption/reduction mechanism and O-speciation.

Understanding if electron transfer precedes the adsorption step is key to further elucidation of the site distribution required to produce a particular product distribution. Three regimes could be adequately distinguished: (1) electron transfer is concurrent to each step in the oxygen reduction mechanism, (2) the barrier to electron transfer is greater than the barrier to the steps involved in oxygen reduction, and (3) the barrier to electron transfer is less than the barrier involved in oxygen reduction steps. The competition between these effects is depicted in the surface coverage of adsorbed oxygen, electrophilic oxygen species and nucleophilic (lattice) oxygen species. 


\section{Multiplicity of steady-states during selective oxidation of propane}

Various acrylic acid selectivities were observed at the same propane conversion. ${ }^{48}$ The selectivity-conversion steady-state data showed a hysteresis effect typically attributed to non-linear mechanisms ${ }^{7}$ and two selectivity values at constant conversion (figures 2 - 4) under the same conditions. Multiplicity occurs when surface reactions are rate-controlling steps on the catalyst grain level. ${ }^{38}$

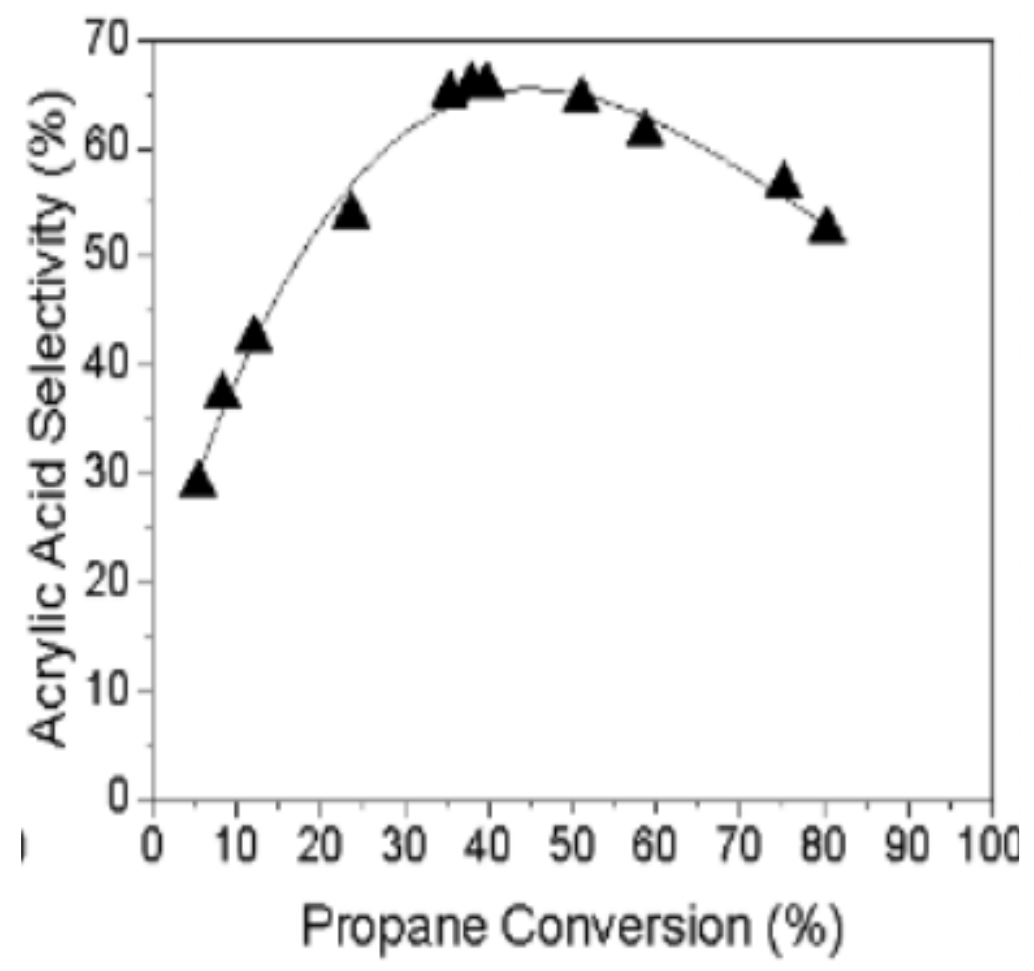

Figure 2: Acrylic acid selectivity-propane conversion curve at constant temperature. Diagram reproduced from supplementary information in Figure 2 in ref. ${ }^{31}$ 


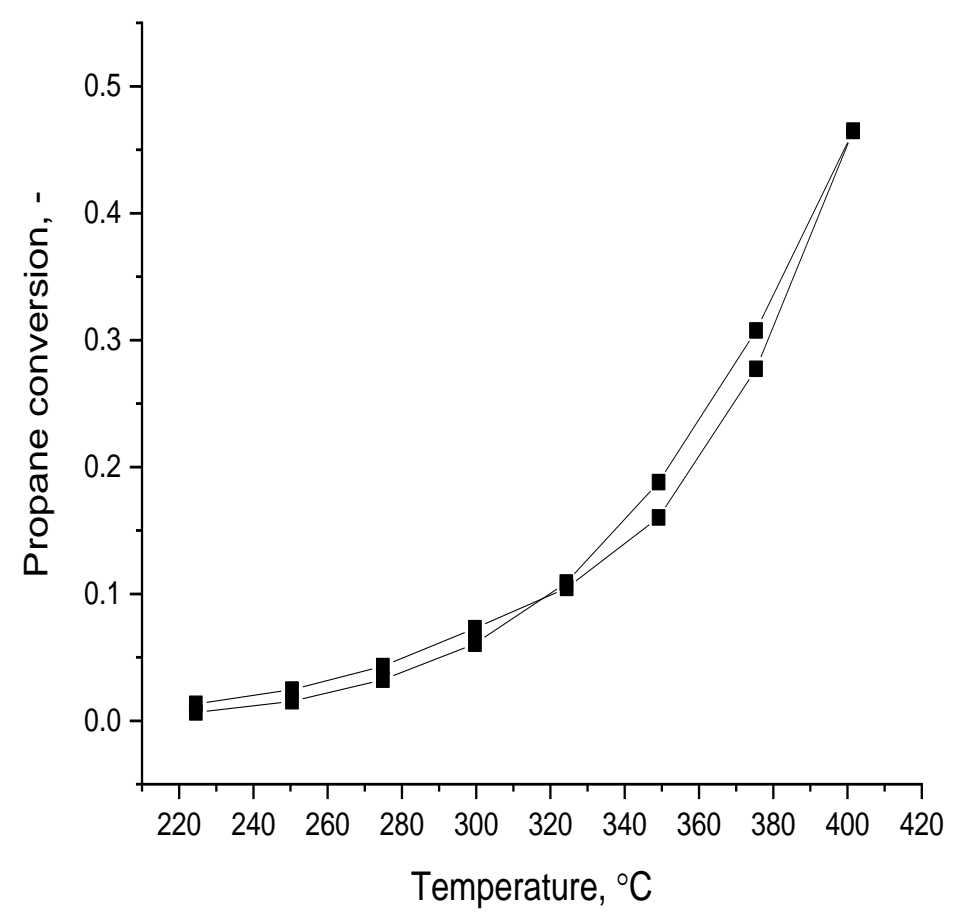

Figure 3: Hysteresis loop obtained during propane conversion over MoVTeNbOx catalysts. Adapted from Figure 4 in ref. ${ }^{31}$

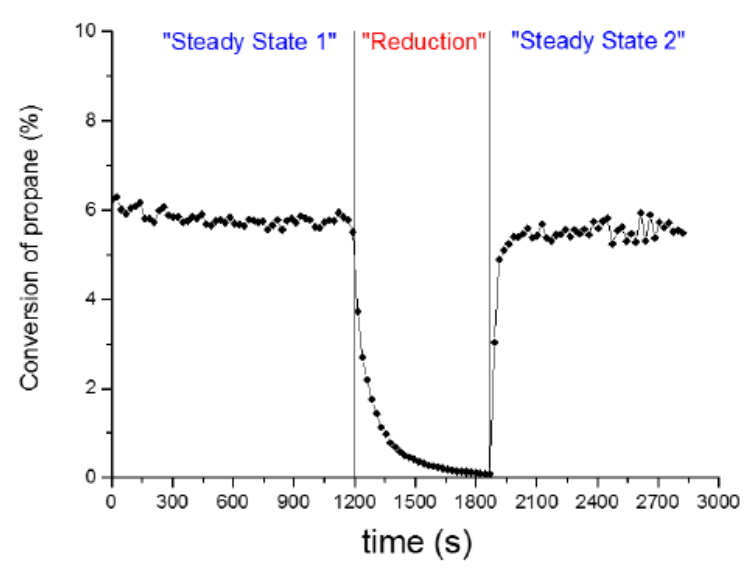

(a)

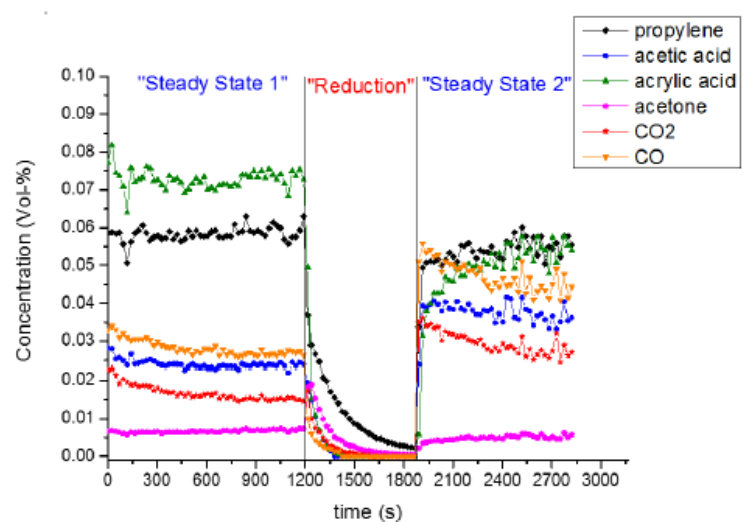

(b)

Figure 3: Catalyst behaviour under reducing and oxidising conditions: (a) propane conversion; (b) Concentration of formed products: "Steady State 1" feed $\left(\mathrm{C}_{3} \mathrm{H}_{8} / \mathrm{O}_{2} / \mathrm{He} / \mathrm{H}_{2} \mathrm{O}=3 / 12 / 75 / 10\right)$, "Reduction" feed $\left(\mathrm{C}_{3} \mathrm{H}_{8} / \mathrm{O}_{2} / \mathrm{He} / \mathrm{H}_{2} \mathrm{O}=3 / 0 / 87 / 10\right)$, and "Steady State 2" feed $\left(\mathrm{C}_{3} \mathrm{H}_{8} / \mathrm{O}_{2} / \mathrm{He} / \mathrm{H}_{2} \mathrm{O}=3 / 12 / 75 / 10\right)$; reaction temperature is $573 \mathrm{~K}$. Reprinted from Ref. ${ }^{32}$

Six possible steady-state solutions based on coverage-dependent multiplicity are provided. 


\subsection{Steady-state solution 1}

In the kinetic equations described below, $\mathrm{ki}^{+}$signifies the rate constant for the forward reaction of the "ith" step. Conversely, $\mathrm{k}_{i}$ signifies the rate constant for the reverse reaction of the "ith" step. Given the following reaction steps:

1. $2 \mathrm{~S}+\mathrm{O}_{2} \rightleftharpoons 2 \mathrm{SO}$

2. $R+S-O \rightarrow R-O+S$

$\frac{d \theta_{S O}}{d t}=2 k_{1}^{+} P_{O 2}\left(1-\theta_{S O}\right)^{2}-2 k_{1}^{-} \theta_{S O}^{2}-k_{2}^{+} P_{R} \theta_{S o}=0$

$n_{R}=k_{2}^{+} P_{R} \theta_{S O}$

$2 k_{1}^{+} P_{O 2}\left(1-\theta_{S O}\right)^{2}-2 k_{1}^{-} \theta_{S O}^{2}-k_{2}^{+} P_{R} \theta_{S o}=0$

$2 k_{1}^{+} P_{O 2}\left(1-2 \theta_{S O}+\theta_{S O}^{2}\right)-2 k_{1}^{-} \theta_{S O}^{2}-k_{2}^{+} P_{R} \theta_{S o}=0$

$2 k_{1}^{+} P_{O 2}-4 k_{1}^{+} P_{O 2} \theta_{S O}+2 k_{1}^{+} P_{O 2} \theta_{S O}^{2}-2 k_{1}^{-} \theta_{S O}^{2}-k_{2}^{+} P_{R} \theta_{S o}=0$

$\left(2 k_{1}^{+} P_{O 2}-2 k_{1}^{-}\right) \theta_{S O}^{2}-\left(k_{2}^{+} P_{R}+4 k_{1}^{+} P_{O 2}\right) \theta_{S o}+2 k_{1}^{+} P_{O 2}=0$

$\theta_{S o}=\frac{\left(k_{2}^{+} P_{R}+4 k_{1}^{+} P_{O 2}\right) \pm \sqrt{\left(k_{2}^{+} P_{R}+4 k_{1}^{+} P_{O 2}\right)^{2}-\left[(4)\left(2 k_{1}^{+} P_{O 2}-2 k_{1}^{-}\right)\left(2 k_{1}^{+} P_{O 2}\right)\right.}}{\left(4 k_{1}^{+} P_{O 2}-4 k_{1}^{-}\right)}$

$\theta_{S o}=\frac{\left(k_{2}^{+} P_{R}+4 k_{1}^{+} P_{O 2}\right) \pm \sqrt{\left(k_{2}^{+} P_{R}\right)^{2}+8 k_{1}^{+} k_{2}^{+} P_{R} P_{O 2}+16 k_{1}^{+} k_{1}^{-} P_{O 2}}}{\left(4 k_{1}^{+} P_{O 2}-4 k_{1}^{-}\right)}$

$\theta_{S O}$ has two solutions, namely:

$\theta_{S O}=\frac{\left(k_{2}^{+} P_{R}+4 k_{1}^{+} P_{O 2}\right)+\sqrt{\left(k_{2}^{+} P_{R}\right)^{2}+8 k_{1}^{+} k_{2}^{+} P_{R} P_{O 2}+16 k_{1}^{+} k_{1}^{-} P_{O 2}}}{\left(4 k_{1}^{+} P_{O 2}-4 k_{1}^{-}\right)}$

And

$\theta_{S O}=\frac{\left(k_{2}^{+} P_{R}+4 k_{1}^{+} P_{O 2}\right)-\sqrt{\left(k_{2}^{+} P_{R}\right)^{2}+8 k_{1}^{+} k_{2}^{+} P_{R} P_{O 2}+16 k_{1}^{+} k_{1}^{-} P_{O 2}}}{\left(4 k_{1}^{+} P_{O 2}-4 k_{1}^{-}\right)}$ 
Solution 2.16 always exists and inserting it into the rate equation would produce the first steady-state rate observed at a particular temperature. Solution 2.17 would only exist when $\left(k_{2}^{+} P_{R}\right)^{2} \gg 8 k_{1}^{+} k_{2}^{+} P_{R} P_{O 2}+16 k_{1}^{+} k_{1}^{-} P_{O 2}$. This occurs when oxygen lean conditions are used such that $\mathrm{P}_{\mathrm{O} 2}$ tends to zero and/or oxygen adsorption on surface vacancies is slow, such that $k_{1}^{+}$is small. The results obtained by ref ${ }^{40,48,49}$ were of oxygen rich conditions indicating that, if the above model is correct, slow oxygen adsorption occurs over MoVTeNb oxide (M1 phase) catalysts at these conditions for this hysteresis to occur. Nonetheless, the solutions show that at steady-state, two different coverages are obtained alluding to the dynamic nature of these active sites (vide infra). It is important to note here that this model does not include the influence of steam during selective oxidation, which plays a huge role in the hysteresis and multiplicity effects observed by ref ${ }^{40,48,49}$. 


\subsection{Steady-state solution 2}

Here, we consider if catalyst restructuring in a simple macrokinetic model would lead to active site dynamics. Suppose we have the following global scheme:

1. $2 S_{1}+O_{2} \rightleftharpoons 2 S_{1}-O$

2. $S_{1}-O+S_{2} \rightleftharpoons S_{2}-O+S_{1}$

3. $R+S_{1}-O \rightarrow R-O+S_{1}$

4. $R+S_{2}-O \rightarrow R-O+S_{2}$

$$
n_{R}=k_{3}^{+} P_{R} \theta_{S 1-O}+k_{4}^{+} P_{R} \theta_{S 2-O}
$$$$
\frac{d \theta_{S 1-O}}{d t}=0=2 k_{1}^{+} P_{O 2}\left(1-\theta_{S 1-o}\right)^{2}-2 k_{1}^{-} \theta_{S 1-O}^{2}-k_{2}^{+} \theta_{S 1-o}\left(1-\theta_{S 2-o}\right)
$$$$
+k_{2}^{-} \theta_{S 2-o}\left(1-\theta_{S 1-O}\right)-k_{3}^{+} P_{R} \theta_{S 1-O}
$$

$$
\begin{gathered}
2 k_{1}^{+} P_{O 2}-4 k_{1}^{+} P_{O 2} \theta_{S 1-O}+2 k_{1}^{+} P_{O 2} \theta_{S 1-O}^{2}-2 k_{1}^{-} \theta_{S 1-O}^{2}-k_{2}^{+} \theta_{S 1-O}+k_{2}^{+} \theta_{S 1-o} \theta_{S 2-O} \\
+k_{2}^{-} \theta_{S 2-O}-k_{2}^{-} \theta_{S 2-o} \theta_{S 1-O}-k_{3}^{+} P_{R} \theta_{S 1-O}=0 \\
\left(2 k_{1}^{+} P_{O 2}-2 k_{1}^{-}\right) \theta_{S 1-O}^{2}-\left(4 k_{1}^{+} P_{O 2}+k_{2}^{+}-k_{2}^{+} \theta_{S 2-O}+k_{2}^{-} \theta_{S 2-O}+k_{3}^{+} P_{R}\right) \theta_{S 1-O}+2 k_{1}^{+} P_{O 2} \\
+k_{2}^{-} \theta_{S 2-O}=0
\end{gathered}
$$

but

$$
\begin{aligned}
& \frac{d \theta_{S 2-O}}{d t}=0=k_{2}^{+} \theta_{S 1-O}\left(1-\theta_{S 2-O}\right)-k_{2}^{-} \theta_{S 2-O}\left(1-\theta_{S 1-O}\right)-k_{4}^{+} P_{R} \theta_{S 2-O} \\
& k_{2}^{+} \theta_{S 1-O}-k_{2}^{+} \theta_{S 1-O} \theta_{S 2-O}-k_{2}^{-} \theta_{S 2-O}+k_{2}^{-} \theta_{S 2-O} \theta_{S 1-O}-k_{4}^{+} P_{R} \theta_{S 2-O}=0 \\
& \theta_{S 2-O}=\frac{k_{2}^{+} \theta_{S 1-O}}{\left(k_{2}^{+} \theta_{S 1-O}+k_{2}^{-}-k_{2}^{-} \theta_{S 1-O}+k_{4}^{+} P_{R}\right)}
\end{aligned}
$$

We observe here that $\theta_{S 2-o}$ has only one solution. In the above scheme, kinetic linearity in observed with respect to $\theta_{S 2-O}$.

Assuming that $k_{4}^{+}$is large, then

$$
\theta_{S 2-O}=\frac{k_{2}^{+} \theta_{S 1-O}}{k_{4}^{+} P_{R}}
$$


Substituting $\theta_{S 2-O}$ in the above, we obtain

$$
\begin{aligned}
& \left(2 k_{1}^{+} P_{O 2}-2 k_{1}^{-}\right) \theta_{S 1-O}^{2}-\left(4 k_{1}^{+} P_{O 2}+k_{2}^{+}-k_{2}^{+}\left(\frac{k_{2}^{+} \theta_{S 1-O}}{k_{4}^{+} P_{R}}\right)+k_{2}^{-}\left(\frac{k_{2}^{+} \theta_{S 1-O}}{k_{4}^{+} P_{R}}\right)+k_{3}^{+} P_{R}\right) \theta_{S 1-O} \\
& +2 k_{1}^{+} P_{O 2}+k_{2}^{-}\left(\frac{k_{2}^{+} \theta_{S 1-O}}{k_{4}^{+} P_{R}}\right)=0 \\
& \left(2 k_{1}^{+} P_{O 2}-2 k_{1}^{-}+\frac{\left(k_{2}^{+}\right)^{2}}{k_{4}^{+} P_{R}}-\frac{k_{2}^{-} k_{2}^{+}}{k_{4}^{+} P_{R}}\right) \theta_{S 1-O}^{2}-\left(4 k_{1}^{+} P_{O 2}+k_{2}^{+}+k_{3}^{+} P_{R}-\frac{k_{2}^{-} k_{2}^{+}}{k_{4}^{+} P_{R}}\right) \theta_{S 1-O} \\
& +2 k_{1}^{+} P_{O 2}=0 \\
& \theta_{S 1-O}=\frac{\left(4 k_{1}^{+} P_{O 2}+k_{2}^{+}+k_{3}^{+} P_{R}-\frac{k_{2}^{-} k_{2}^{+}}{k_{4}^{+}}\right) \pm \sqrt{\left(4 k_{1}^{+} P_{O 2}+k_{2}^{+}+k_{3}^{+} P_{R}-\frac{k_{2}^{-} k_{2}^{+}}{k_{4}^{+} P_{R}}\right)^{2}-\left(4 k_{1}^{+} P_{O 2}\right)^{2}+16 k_{1}^{-} k_{1}^{+} P_{O 2}-\frac{8 k_{1}^{+}\left(k_{2}^{+}\right)^{2} P_{O 2}}{k_{4}^{+} P_{R}}+\frac{8 k_{1}^{+} k_{2}^{-} k_{2}^{+} P_{O 2}}{k_{4}^{+} P_{R}}}}{\left(4 k_{1}^{+} P_{O 2}-4 k_{1}^{-}+\frac{2\left(k_{4}^{+}\right)^{2}}{k_{4}^{+} P_{R}}-\frac{2 k_{2}^{-} k_{2}^{+}}{k_{4}^{+} P_{R}}\right)} \\
& \left(4 k_{1}^{+} P_{O 2}+k_{2}^{+}+k_{3}^{+} P_{R}-\frac{k_{2}^{-} k_{2}^{+}}{k_{4}^{+} P_{R}}\right) \pm \sqrt{8 k_{1}^{+} k_{2}^{+} P_{O 2}+8 k_{1}^{+} k_{3}^{+} P_{O 2} P_{R}+2 k_{2}^{+} k_{3}^{+} P_{R}-\frac{8 k_{1}^{+} k_{2}^{-} k_{2}^{+} P_{O 2}}{k_{4}^{+} P_{R}}-\frac{2 k_{2}^{-}\left(k_{2}^{+}\right)^{2}}{k_{4}^{+} P_{R}}-\frac{2 k_{2}^{+} k_{2}^{-} k_{3}^{+}}{k_{4}^{+}}+\left(k_{2}^{+}\right)^{2}+\left(k_{3}^{+} P_{R}\right)^{2}+\left(\frac{k_{2}^{-} k_{2}^{+}}{k_{4}^{+} P_{R}}\right)^{2}+16 k_{1}^{-} k_{1}^{+} P_{O 2}-\frac{8 k_{1}^{+}\left(k_{2}^{+}\right)^{2} P_{O 2}}{k_{4}^{+} P_{R}}+\frac{8 k_{1}^{+} k_{2}^{-} k_{2}^{+} P_{O 2}}{k_{4}^{+} P_{R}}} \\
& \left(4 k_{1}^{+} P_{O 2}-4 k_{1}^{-}+\frac{2\left(k_{2}^{+}\right)^{2}}{k_{4}^{+} P_{R}}-\frac{2 k_{2}^{-} k_{2}^{+}}{k_{4}^{+} P_{R}}\right) \\
& =\frac{\left(4 k_{1}^{+} P_{O 2}+k_{2}^{+}+k_{3}^{+} P_{R}-\frac{k_{2}^{-} k_{2}^{+}}{k_{4}^{+} P_{R}}\right) \pm \sqrt{8 k_{1}^{+} k_{2}^{+} P_{O 2}+8 k_{1}^{+} k_{3}^{+} P_{O 2} P_{R}+2 k_{2}^{+} k_{3}^{+} P_{R}-\frac{2 k_{2}^{-}\left(k_{2}^{+}\right)^{2}}{k_{4}^{+} P_{R}}-\frac{2 k_{2}^{+} k_{2}^{-} k_{3}^{+}}{k_{4}^{+}}+\left(k_{2}^{+}\right)^{2}+\left(k_{3}^{+} P_{R}\right)^{2}+\left(\frac{k_{2}^{-} k_{2}^{+}}{k_{4}^{+} P_{R}}\right)^{2}+16 k_{1}^{-} k_{1}^{+} P_{O 2}-\frac{8 k_{1}^{+}\left(k_{2}^{+}\right)^{2} P_{O 2}}{k_{4}^{+} P_{R}}}}{\left(4 k_{1}^{+} P_{O 2}-4 k_{1}^{-}+\frac{2\left(k_{2}^{+}\right)^{2}}{k_{4}^{+} P_{R}}-\frac{2 k_{2}^{-} k_{2}^{+}}{k_{4}^{+} P_{R}}\right)}
\end{aligned}
$$

Assuming $k_{3}^{+}$and $k_{4}^{+}$are large, then

$\theta_{S 1-O}=\frac{\left(k_{3}^{+} P_{R}\right) \pm \sqrt{8 k_{1}^{+} k_{3}^{+} P_{O 2} P_{R}+2 k_{2}^{+} k_{3}^{+} P_{R}+\left(k_{3}^{+} P_{R}\right)^{2}}}{\left(4 k_{1}^{+} P_{O 2}-4 k_{1}^{-}\right)}$

In the above, $\theta_{S 1-O}$ can only have one positive solution. Consequently, $\theta_{S 2-O}$ will only have one positive solution and only one steady-state will be observed. Hysteresis cannot be observed if alkane oxidation is fast on both the original (clean) and the restructured (modified) surface. 


\subsection{Steady-state solution 3}

Multiplicity in the values of $\theta_{S 2-O}$ may be observed if molecular oxygen adsorption occurs on the restructured surface leading to a non-linear scheme. The following scheme applies:

1. $2 S_{1}+O_{2} \rightleftharpoons 2 S_{1}-O$

2. $2 S_{2}+O_{2} \rightleftharpoons 2 S_{2}-O$

3. $S_{1}-O+S_{2} \rightleftharpoons S_{2}-O+S_{1}$

4. $R+S_{1}-O \rightarrow R-O+S_{1}$

5. $\quad R+S_{2}-O \rightarrow R-O+S_{2}$

$n_{R}=k_{4}^{+} P_{R} \theta_{S 1-o}+k_{5}^{+} P_{R} \theta_{S 2-o}$

$\frac{d \theta_{S 1-0}}{d t}=2 k_{1}^{+}\left(1-\theta_{S 1-O}\right)^{2} P_{O 2}-2 k_{1}^{-} \theta_{S 1-O}^{2}-k_{3}^{+} \theta_{S 1-O}\left(1-\theta_{S 2-O}\right)+k_{3}^{-} \theta_{S 2-o}\left(1-\theta_{S 1-O}\right)$

$$
-k_{4}^{+} P_{R} \theta_{S 1-o}=0
$$

$\left(2 k_{1}^{+} P_{O 2}-2 k_{1}^{-}\right) \theta_{S 1-O}^{2}-\left(4 k_{1}^{+} P_{O 2}+k_{3}^{+}-k_{3}^{+} \theta_{S 2-O}+k_{3}^{-} \theta_{S 2-O}-k_{4}^{+} P_{R}\right) \theta_{S 1-O}$

$$
+\left(2 k_{1}^{+} P_{O 2}+k_{3}^{-} \theta_{S 2-o}\right)=0
$$

At high $\mathrm{k}_{4}^{+}$or $\mathrm{k}_{5}^{+}$;

$\theta_{S 1-o}=\frac{-k_{4}^{+} P_{R} \pm \sqrt{\left(k_{4}^{+} P_{R}\right)^{2}-8 k_{1}^{+} k_{4}^{+} P_{O 2} P_{R}-2 k_{3}^{+} k_{4}^{+} P_{R}+2 k_{3}^{+} k_{4}^{+} P_{R} \theta_{S 2-o}-2 k_{3}^{-} k_{4}^{+} P_{R} \theta_{S 2-o}}}{4 k_{1}^{+} P_{O 2}-4 k_{1}^{-}}$

$\theta_{S 1-O}$ has only one real solution when $\left(\left(k_{4}^{+} P_{R}\right)^{2}+2 k_{3}^{+} k_{4}^{+} P_{R} \theta_{S 2-O}\right) \gg\left(8 k_{1}^{+} k_{4}^{+} P_{O 2} P_{R}+\right.$ $\left.2 k_{3}^{+} k_{4}^{+} P_{R}+2 k_{3}^{-} k_{4}^{+} P_{R} \theta_{S 2-o}\right)$

$\theta_{S 2-o}=\frac{-k_{5}^{+} P_{R} \pm \sqrt{\left(k_{5}^{+} P_{R}\right)^{2}+8 k_{2}^{+} k_{5}^{+} P_{O 2} P_{R}+2 k_{3}^{-} k_{5}^{+} P_{O 2}+2 k_{3}^{+} k_{5}^{+} P_{R} \theta_{S 1-O}-2 k_{3}^{-} k_{5}^{+} P_{R} \theta_{S 1-o}}}{4 k_{1}^{+} P_{O 2}-4 k_{1}^{-}}$

$\theta_{S 2-O}$ has only one real solution when $\left(\left(k_{5}^{+} P_{R}\right)^{2}+8 k_{2}^{+} k_{5}^{+} P_{O 2} P_{R}+2 k_{3}^{-} k_{5}^{+} P_{O 2}+\right.$ $\left.2 k_{3}^{+} k_{5}^{+} P_{R} \theta_{S 1-o}\right) \gg 2 k_{3}^{-} k_{5}^{+} P_{R} \theta_{S 1-o}$

Consequently, this model system has only one real solution and does not provide a basis for multiplicity of steady-state observed. 


\subsection{Steady-state solution 4}

Multiplicity could occur due to the presence of water vapour in a single active site.

Considering the following stoichiometry given as:

1. $2 \mathrm{~S}+\mathrm{O}_{2} \rightleftharpoons 2 \mathrm{SO}$

2. $\mathrm{H}_{2} \mathrm{O}+\mathrm{S}-\mathrm{O}+\mathrm{S} \rightleftharpoons 2 \mathrm{~S}-\mathrm{OH}$

3. $\mathrm{R}+2 \mathrm{~S}-\mathrm{OH} \rightarrow \mathrm{RH}_{2}+2 \mathrm{~S}-\mathrm{O}$

$n_{R}=k_{3}^{+} P_{R} \theta_{S O H}^{2}$

$\frac{d \theta_{S O}}{d t}=2 k_{1}^{+} P_{O 2}\left(1-\theta_{S O}-\theta_{S O H}\right)^{2}-2 k_{1}^{-} \theta_{S O}^{2}-k_{2}^{+} P_{H 2 O} \theta_{S O}\left(1-\theta_{S O}-\theta_{S O H}\right)+k_{2}^{-} \theta_{S O H}^{2}$ $+2 k_{3}^{+} P_{R} \theta_{S O H}^{2}$

$\left(1-\theta_{S O}-\theta_{S O H}\right)^{2}=1-\theta_{S O}-\theta_{S O H}-\theta_{S O}+\theta_{S O}^{2}+\theta_{S O} \theta_{S O H}-\theta_{S O H}+\theta_{S O} \theta_{S O H}+\theta_{S O H}^{2}$ $=1-2 \theta_{S O}-2 \theta_{S O H}+2 \theta_{S O} \theta_{S O H}+\theta_{S O}^{2}+\theta_{S O H}^{2}$

$\frac{d \theta_{S O}}{d t}=2 k_{1}^{+} P_{O 2}-4 k_{1}^{+} P_{O 2} \theta_{S O}-4 k_{1}^{+} P_{O 2} \theta_{S O H}+4 k_{1}^{+} P_{O 2} \theta_{S O} \theta_{S O H}+4 k_{1}^{+} P_{O 2} \theta_{S O}^{2}$

$+4 k_{1}^{+} P_{\mathrm{O} 2} \theta_{\mathrm{SOH}}^{2}-2 k_{1}^{-} \theta_{\mathrm{SO}}^{2}-k_{2}^{+} P_{\mathrm{H} 2 \mathrm{O}} \theta_{\mathrm{SO}}+k_{2}^{+} P_{\mathrm{H} 2 \mathrm{O}} \theta_{\mathrm{SO}}^{2}+k_{2}^{+} P_{\mathrm{H} 2 \mathrm{O}} \theta_{\mathrm{SO}} \theta_{\mathrm{SOH}}$

$+k_{2}^{-} \theta_{S O H}^{2}+2 k_{3}^{+} P_{R} \theta_{S O H}^{2}$

$\theta_{S O}^{2}\left(4 k_{1}^{+} P_{O 2}-2 k_{1}^{-}+k_{2}^{+} P_{H 2 O}\right)-\theta_{S O}\left(4 k_{1}^{+} P_{O 2}-4 k_{1}^{+} P_{O 2} \theta_{S O H}+k_{2}^{+} P_{H 2 O}-k_{2}^{+} P_{H 2 O} \theta_{S O H}\right)$

$+2 k_{1}^{+} P_{O 2}-4 k_{1}^{+} P_{O 2} \theta_{S O H}+4 k_{1}^{+} P_{O 2} \theta_{S O H}^{2}+k_{2}^{-} \theta_{S O H}^{2}+2 k_{3}^{+} P_{R} \theta_{S O H}^{2}=0$

$\frac{d \theta_{S O H}}{d t}=2 k_{2}^{+} P_{H 2 O} \theta_{S O}\left(1-\theta_{S O}-\theta_{S O H}\right)-2 k_{2}^{-} \theta_{S O H}^{2}-k_{3}^{+} P_{R} \theta_{S O H}^{2}=0$

$\theta_{\mathrm{SOH}}^{2}\left(2 k_{2}^{-}+k_{3}^{+} P_{R}\right)+2 k_{2}^{+} P_{\mathrm{H} 2 \mathrm{O}} \theta_{\mathrm{SO}} \theta_{\mathrm{SOH}}-2 k_{2}^{+} P_{\mathrm{H} 2 \mathrm{O}} \theta_{\mathrm{SO}}+2 k_{2}^{+} P_{\mathrm{H} 2 \mathrm{O}} \theta_{\mathrm{SO}}^{2}=0$

$\theta_{S O H}=\frac{-2 k_{2}^{+} P_{H 2 O} \theta_{S O}-\sqrt{4\left(k_{2}^{+}\right)^{2} P_{H 2 O}^{2} \theta_{S O}^{2}+32 k_{2}^{-} k_{2}^{+} P_{H 2 O} \theta_{S O}-16 k_{2}^{+} k_{2}^{-} P_{H 2 O} \theta_{S O}^{2}-8 k_{3}^{+} k_{2}^{+} P_{R} P_{H 2 O} \theta_{S O}^{2}}}{2 k_{2}^{-}+2 k_{3}^{+} P_{R}}$

OR

$\theta_{S O H}=\frac{-2 k_{2}^{+} P_{H 2 O} \theta_{S O}+\sqrt{4\left(k_{2}^{+}\right)^{2} P_{H 2 O}^{2} \theta_{S O}^{2}+32 k_{2}^{-} k_{2}^{+} P_{H 2 O} \theta_{S O}-16 k_{2}^{+} k_{2}^{-} P_{H 2 O} \theta_{S O}^{2}-8 k_{3}^{+} k_{2}^{+} P_{R} P_{H 2 O} \theta_{S O}^{2}}}{2 k_{2}^{-}+2 k_{3}^{+} P_{R}}$ 


$$
\begin{aligned}
\tau=-16\left(k_{1}^{+} P_{\mathrm{O} 2}\right)^{2}+32\left(k_{1}^{+} P_{\mathrm{O} 2}\right)^{2} \theta_{\mathrm{SOH}}-32 k_{1}^{+} P_{\mathrm{O} 2} k_{2}^{+} P_{\mathrm{H} 2 \mathrm{O}} \theta_{\mathrm{SOH}}-8 k_{1}^{+} P_{\mathrm{O} 2} k_{2}^{+} P_{\mathrm{H} 2 \mathrm{O}} \theta_{\mathrm{SOH}}^{2} \\
-2\left(k_{2}^{+} P_{\mathrm{H} 2 \mathrm{O}}\right)^{2} \theta_{\mathrm{SOH}}+\left(k_{2}^{+} P_{\mathrm{H} 2 \mathrm{O}}\right)^{2}+\left(k_{2}^{+} P_{\mathrm{H} 2 \mathrm{O}} \theta_{\mathrm{SOH}}\right)^{2}-64\left(k_{1}^{+} P_{\mathrm{O} 2} \theta_{\mathrm{SOH}}\right)^{2} \\
-16 k_{1}^{+} P_{\mathrm{O} 2} k_{2}^{-} \theta_{\mathrm{SOH}}^{2}-32 k_{1}^{+} P_{\mathrm{O} 2} k_{3}^{+} \theta_{\mathrm{SOH}}^{2}+16 k_{1}^{+} P_{\mathrm{O} 2} k_{1}^{-}-32 k_{1}^{+} P_{\mathrm{O} 2} k_{1}^{-} \theta_{\mathrm{SOH}} \\
+32 k_{1}^{+} P_{\mathrm{O} 2} k_{1}^{-} \theta_{\mathrm{SOH}}^{2}+8 k_{1}^{-} k_{2}^{-} \theta_{\mathrm{SOH}}^{2}+16 k_{1}^{-} k_{3}^{+} P_{R} \theta_{\mathrm{SOH}}^{2}-4 k_{2}^{+} P_{\mathrm{H} 2 \mathrm{O}} k_{2}^{-} \theta_{\mathrm{SOH}}^{2} \\
-8 k_{2}^{+} P_{\mathrm{H} 2 \mathrm{O}} k_{3}^{+} P_{\mathrm{R}} \theta_{\mathrm{SOH}}^{2}
\end{aligned}
$$

Depending on the magnitude of $\tau, \theta_{S O}$ has two possible solutions (even when $\theta_{S O H}$ has only one possible solution).

In the four models (steady-state solutions 3.1-3.4) described above, in accordance with archived literature ${ }^{7}$, multiplicity of steady-states requires non-linearity of the chemical equations (steady-state solution 3.1 and 3.4). This means oxygen adsorption should be lumped. Micro-deconvolution of the oxygen adsorption step involves non-linearity and would provide information on rules governing targeted selectivity as suggested by Panov. ${ }^{28}$

Experimental data shows accurately an hysteresis loop 48,50 associated with selective oxidation showing that the non-linearity of the oxygen mechanism is not the only factor governing hysteresis and multiplicity. ${ }^{7}$ The presence of steam leading to non-linearity leads to the multiplicity observed under steady-state conditions. Also, different active centres may be responsible. ${ }^{51}$ Decoupling the lumped oxygen adsorption step does not lead to solution linearity.

$$
\begin{aligned}
& \frac{d \theta_{S 2-0}}{d t}=2 k_{2}^{+}\left(1-\theta_{S 2-O}\right)^{2} P_{O 2}-2 k_{2}^{-} \theta_{S 2-O}^{2}+k_{3}^{+} \theta_{S 1-O}\left(1-\theta_{S 2-O}\right)-k_{3}^{-} \theta_{S 2-O}\left(1-\theta_{S 1-O}\right) \\
& -k_{5}^{+} P_{R} \theta_{S 2-O}=0 \\
& \left(2 k_{2}^{+} P_{O 2}-2 k_{2}^{-}\right) \theta_{S 2-O}^{2}-\left(4 k_{2}^{+} P_{O 2}+k_{3}^{-}+k_{3}^{+} \theta_{S 1-O}-k_{3}^{-} \theta_{S 1-O}-k_{5}^{+} P_{R}\right) \theta_{S 1-O} \\
& +\left(2 k_{2}^{+} P_{O 2}+k_{3}^{+} \theta_{S 1-O}\right)=0
\end{aligned}
$$


At high $\mathrm{k}^{+}$or $\mathrm{k}^{+}$;

$\theta_{S 2-O}=\frac{-k_{5}^{+} P_{R} \pm \sqrt{\left(k_{5}^{+} P_{R}\right)^{2}+8 k_{2}^{+} k_{5}^{+} P_{O 2} P_{R}+2 k_{3}^{-} k_{5}^{+} P_{O 2}+2 k_{3}^{+} k_{5}^{+} P_{R} \theta_{S 1-O}-2 k_{3}^{-} k_{5}^{+} P_{R} \theta_{S 1-O}}}{4 k_{1}^{+} P_{O 2}-4 k_{1}^{-}}$

$\theta_{S 2-O}$ has only one real solution when $\left(\left(k_{5}^{+} P_{R}\right)^{2}+8 k_{2}^{+} k_{5}^{+} P_{O 2} P_{R}+2 k_{3}^{-} k_{5}^{+} P_{O 2}+\right.$ $\left.2 k_{3}^{+} k_{5}^{+} P_{R} \theta_{S 1-O}\right) \gg 2 k_{3}^{-} k_{5}^{+} P_{R} \theta_{S 1-O}$

Consequently, this model system has only one real solution and does not provide a basis for multiplicity of steady-state observed.

\subsection{Steady-state solution 5}

Multiplicity of steady-state can be obtained with respect to "modified" surfaces in selective oxidation. A suitable scheme is given below for the selective oxidation of propane to acrylic acid over MoVTeNbOx catalyst particles ( $\mathrm{M}=$ vanadium, $\mathrm{L}=$ Tellurium):

1. $2 \mathrm{M}+\mathrm{O}_{2} \rightleftharpoons 2 \mathrm{MO}$

2. $\quad R+M-O \rightarrow R-O+M$

Following the proposal by Glemser et al. ${ }^{42,43}$ and Sanfiz et al. ${ }^{40,52}$, in the presence of steam, the tellurium cations could be adsorption sites for oxygen.

3. $\quad \mathrm{L}+\mathrm{O}_{2} \rightleftharpoons \mathrm{LO}_{2}$

4. $\quad 2 \mathrm{~L}+\mathrm{O}_{2} \rightleftharpoons 2 \mathrm{LO}$

5. $\mathrm{H}_{2} \mathrm{O}+\mathrm{LO}_{2} \rightleftharpoons \mathrm{LO}(\mathrm{OH})_{2, a d s}$

6. $\mathrm{LO}(\mathrm{OH})_{2, a d s} \rightleftharpoons \mathrm{LO}_{2, \text { rest }}+\mathrm{H}_{2} \mathrm{O}$

7. $R+2 \mathrm{LO}_{2, \text { rest }} \rightarrow \mathrm{R}-\mathrm{O}_{2}+2 \mathrm{LO}$

The adsorption of steam and oxygen leads to non-linearity on the tellurium active sites (reactions 1 and 7 in the scheme above). Although, the presence of two adsorption sites ( $\mathrm{MO}$ and $\mathrm{LO}_{2}$,rest) can lead to multiplicity and hysteresis effects ${ }^{53}$ 
shown over MoVTeNb oxide catalysts, ${ }^{40,} 49,50$ reaction 3 introduces linearity in the scheme, which leads to the absence of coverage-dependent multiplicity. The mechanism proposed by Glemser and co-workers ${ }^{42,43}$ has been further re-modified to remove all linear steps, albeit the surface enrichment of tellurium. The kinetics is considered in section 3.6.

\subsection{Steady-state solution 6}

Solution 5 was adapted to produce solution 6 .

1. $2 \mathrm{M}+\mathrm{O}_{2} \rightleftharpoons 2 \mathrm{MO}$

2. $R+M-O \rightarrow R-O+M$

3. $2 \mathrm{~L}+\mathrm{O}_{2} \rightleftharpoons 2 \mathrm{LO}$

4. $\mathrm{H}_{2} \mathrm{O}+2 \mathrm{LO} \rightleftharpoons \mathrm{LO}(\mathrm{OH})_{2}+\mathrm{L}$

5. $\mathrm{LO}(\mathrm{OH})_{2} \rightleftharpoons \mathrm{LO}_{2, \text { rest }}+\mathrm{H}_{2} \mathrm{O}$

6. $2 L_{\text {rest }}+\mathrm{O}_{2} \rightleftharpoons 2 \mathrm{LO}_{\text {rest }}$

7. $R+L-O_{\text {rest }} \rightarrow R-O+L_{\text {rest }}$

A combination of equations 1 and 2, and 6 and 7 highlights steady-state multiplicity as given in steady-state solution I. Steady-state multiplicity is obtained when it is assumed that:

$\left[\mathrm{LO}(\mathrm{OH})_{2}\right]$, and $\left[\mathrm{LO}_{2, \text { rest }}\right] \sim 0$ and $\mathrm{P}_{\mathrm{O} 2} \rightarrow \min$

Since the multiplicities arising from 1 and 2, and 6 and 7 are clear (vide infra), we analyse equations 3,4 and 5 :

$\frac{d \theta_{L O}}{d t}=2 k_{3}^{+} P_{O 2} \theta_{L}^{2}-2 k_{3}^{-} \theta_{L O}^{2}-2 k_{4}^{+} P_{H 2 O} \theta_{L O}^{2}+2 k_{4}^{-} \theta_{L O(O H)_{2}} \theta_{L}$

With the assumption above and $\theta_{L}=1-\theta_{\mathrm{LO}}-\theta_{\mathrm{LO}(\mathrm{OH})_{2}} \approx 1-\theta_{\mathrm{LO}}$, we obtain:

$$
\begin{aligned}
& \frac{d \theta_{L O}}{d t}=2 k_{3}^{+} P_{O 2} \theta_{L}^{2}-2 k_{3}^{-} \theta_{L O}^{2}-2 k_{4}^{+} P_{H 2 O} \theta_{L O}^{2} \\
& =2 k_{3}^{+} P_{O 2}-4 k_{3}^{+} \theta_{L O} P_{O 2}-2 k_{3}^{-} \theta_{L O}^{2}-2 k_{4}^{+} P_{H 2 O} \theta_{L O}^{2}=0
\end{aligned}
$$




$$
\begin{aligned}
& \frac{d \theta_{L O}}{d t}=\left(2 k_{3}^{+} P_{O 2}+2 k_{4}^{+} P_{H 2 O}\right) \theta_{L O}^{2}+4 k_{3}^{+} P_{H 2 O} \theta_{L O}-2 k_{3}^{+} P_{O 2}=0 \\
& \theta_{L O}=\frac{-4 k_{3}^{+} P_{H 2 O} \pm \sqrt{\left(4 k_{3}^{+} P_{H 2 O}\right)^{2}+4\left(2 k_{3}^{+} P_{O 2}+2 k_{4}^{+} P_{H 2 O}\right)\left(2 k_{3}^{+}\right)}}{4 k_{3}^{+} P_{O 2}+4 k_{4}^{+} P_{H 2 O}}
\end{aligned}
$$

In 2.28, $\theta_{L O}$ has one solution and $\theta_{L O_{r e s t}}=f\left(\theta_{L O}\right)$ has two feasible solutions because of the multiplicity effect in step 6 of scheme 3.4 .

Thus, it is proven that with restructuring, and in the presence of steam and with two different sites, it is possible to obtain steady-state multiplicity at the catalyst grain level. 


\section{Conclusions}

The Mars and van Krevelen mechanism is widely established for the selective oxidation or oxidative dehydrogenation reactions over multifunctional and multicomponent transition metal and metal oxide catalysts. Following the work of Mars and van Krevelen, and Vannice and co-workers, the kinetics is re-evaluated to introduce recent results from modern operando spectroscopy and microscopy investigations that were not available when the 1954 work of Mars and van Krevelen was published. These include reactions with nucleophilic (lattice) oxygen, reversibility of the oxygen reduction mechanism, an interconversion scheme, non-linear water adsorption, remote-control model, and non-uniform sites. Experimental observations of the multiplicity of propane conversion over MoVTeNbOx is proven theoretically through non-linear competitive steam adsorption, the presence of multiple active sites, a restructuring active site, and oxygen adsorption. Coverage-driven multiplicity depends on the active-site restructuring mechanism, which differs from one catalyst to the other.

\section{Declaration of Competing Interest}

There are no competing financial interests or personal relationships that could have appeared to influence the work reported in this paper 


\section{References}

1. Mars, P.; van Krevelen, D. W., Oxidations carried out by means of vanadium oxide catalysts. Chem. Eng. Sci. 1954, 3, 41-59.

2. Vannice, M. A., An analysis of the Mars-van Krevelen rate expression. Catal. Today 2007, $123(1), 18-22$.

3. Somorjai, G. A.; Park, J. Y., Molecular factors of catalytic selectivity. Angewandte Chemie - International Edition 2008, 47 (48), 9212-9228.

4. Freund, H. J.; Kuhlenbeck, H.; Staemmler, V., Oxide surfaces. Rep. Prog. Phys. 1996, 59 (3), 283-347.

5. Zhukov, S. A.; Barelko, V. V., Nonuniqueness of stationary states in a catalyzer and flickering in the oxidation of ethylene on platinum. Dokl. Akad. Nauk SSR 1976, 229, $655-660$.

6. Eigenberger, G., Kinetic instabilities in heterogeneously catalyzed reactions-I. Rate multiplicity with langmuir-type kinetics. Chem. Eng. Sci. 1978, 33 (9), 1255-1261.

7. Marin, G. B.; Yablonsky, G. S., Kinetics of Chemical Reactions: Decoding Complexity WILEY-VCH: Weinheim, Germany, 2011; p 1-428.

8. Boreskov, G. K.; Slin'ko, M. G.; Filippova, A. G., Catalytic activity of nickel, palladium, and platinumin hydrogen oxidation. . Dok. Akad. Nauk. SSSR 1953, 92, 353-355.

9. Kharkovskaya, E. N.; Boreskov, G. K.; Slin'ko, M. G., Dok. Akad. Nauk. SSSR 1959, 127, 145-148.

10. Golchet, A.; White, J. M., Rates and Coverages in the low pressure Ptcatalyzed oxidation of carbon monoxide. J. Catal. 1978, 53, 266-279.

11. Salanov, A. N.; Savchenko, V. I., On the nature of hysteresis in the oxidation of carbon monoxide on platinum. Kinet. Katal. 1985, 26, 1136 - 1142.

12. Slin'ko, M. G.; Beskov, V. S.; Dubyaga, N. A., Possibility of the existence of several steady-state modes in kinetically controlled heterogeneous catalytic reactions. Dok. Akad. Nauk. SSSR 1972, 204, 1174-1177.

13. Barelko, V. V.; Volodin, Y. E., Critical phenomena in nonthermal nature in the ammonia oxidation reaction on platinum. Dokl. Akad. Nauk SSR 1973, 211, 1373-1376.

14. Zhukov, S. A.; Barelko, V. V. 2nd All-Union Conference Kinet. Catal. React. (Kinetics-2), Institute of Catalysis, Novosibirsk, Institute of Catalysis, Novosibirsk, 1975; pp 29-32.

15. Bolten, H.; Hahn, T.; LeRoux, J.; Lintz, H. G., Bistability of the reaction rate in the oxidation of carbon monoxide by nitrogen monoxide on polycrystalline platinum. Surf. Sci. 1985, 160, L529 - L532.

16. Beusch, H.; Fieguth, P.; Wicke, E., Thermisch und kinetisch verursachte Instabilitäten im Reaktionsverhalten einzelner Katalysatorkörner. Chem. Ing. Tech. 1972, 44 (7), 445-451.

17. Hugo, P.; Jakubith, M., Dynamisches Verhalten und Kinetik der Kohlenmonoxid-Oxidation am Platin-Katalysator. Chem. Ing. Tech. 1972, 44 (6), 383-387.

18. Belyaev, V. D.; Slinko, M. M.; Slinko, M. G. Proc Int Congr Cat, London, London, 1976.

19. Cant, N. W.; Hall, W. K., Catalytic oxidation. III. The mechanism of ethylene and propylene oxidation over supported rhodium and ruthenium. J. Catal. 1971, 22 (3), 310-323. 
20. Dauchot, J. P.; Cakenberghe, J. V., Oscillations during Catalytic Oxidation of Carbon Monoxide on Platinum. Nature Physical Science 1973, 246 (152), 61 63.

21. Eigenberger, G., Kinetic instabilities in heterogeneously catalyzed reactions-II. Oscillatory instabilities with langmuir-type kinetics. Chem. Eng. Sci. 1978, 33 (9), 1263-1268.

22. Eigenberger, G., On the dynamic behavior of the catalytic fixed-bed reactor in the region of multiple steady states-I. The influence of heat conduction in two phase models. Chem. Eng. Sci. 1972, 27 (11), 1909-1915.

23. Eigenberger, G., On the dynamic behavior of the catalytic fixed-bed reactor in the region of multiple steady states-II. The influence of the boundary conditions in the catalyst phase. Chem. Eng. Sci. 1972, 27 (11), 1917-1924.

24. Eigenberger, G. Habilitationsschrift. Universität Stuttgart, 1977.

25. Andronow, A. A.; Witt, A. H.; Chaukin, S. E., Theorie der Schwingungen, Teil I. Akademise Vlg. Berlin 1965.

26. Suchorski, Y.; Zeininger, J.; Buhr, S.; Raab, M.; Stöger-Pollach, M.; Bernardi, J.; Grönbeck, H.; Rupprechter, G., Resolving multifrequential oscillations and nanoscale interfacet communication in single-particle catalysis. Science 2021, 372 (6548), 1314-1318.

27. Suchorski, Y.; Datler, M.; Bespalov, I.; Zeininger, J.; Stoger-Pollach, M.; Bernardi, J.; Gronbeck, H.; Rupprechter, G., Visualizing catalyst heterogeneity by a multifrequential oscillating reaction. Nat Commun 2018, 9 (1), 600.

28. Panov, G. I.; Dubkov, K. A.; Starokon, E. V., Active oxygen in selective oxidation catalysis. Catal. Today 2006, $117(1-3), 148-155$.

29. Schlögl, R., Heterogeneous Catalysis. Angew. Chem. Int. Ed. 2015, 54 (11), 3465-3520.

30. Delmon, B.; Froment, G. F., Remote control of catalytic sites by spillover species: A chemical reaction engineering approach. Cat. Rev. - Sci. Eng. 1996, 38 (1), 69-100.

31. Trunschke, A.; Bellini, G.; Boniface, M.; Carey, S. J.; Dong, J. H.; Erdem, E.; Foppa, L.; Frandsen, W.; Geske, M.; Ghiringhelli, L. M.; Girgsdies, F.; Hanna, R.; Hashagen, M.; Havecker, M.; Huff, G.; Knop-Gericke, A.; Koch, G.; Kraus, P.; Krohnert, J.; Kube, P.; Lohr, S.; Lunkenbein, T.; Masliuk, L.; d'Alnoncourt, R. N.; Omojola, T.; Pratsch, C.; Richter, S.; Rohner, C.; Rosowski, F.; Ruther, F.; Scheffler, M.; Schlogl, R.; Tarasov, A.; Teschner, D.; Timpe, O.; Trunschke, P.; Wang, Y. Q.; Wrabetz, S., Towards Experimental Handbooks in Catalysis. Top. Catal. 2020, 63 (19-20), 16831699.

32. Sprung, C.; Yablonsky, G. S.; Schlögl, R.; Trunschke, A., Constructing a rational kinetic model of the selective propane oxidation over a mixed metal oxide catalyst. Catalysts 2018, 8 (8).

33. Schlögl, R., Active Sites for Propane Oxidation: Some Generic Considerations. Top. Catal. 2011, 54 (10), 627.

34. Linke, D.; Wolf, D.; Baerns, M.; Timpe, O.; Schlögl, R.; Zeyß, S.; Dingerdissen, U., Catalytic Partial Oxidation of Ethane to Acetic Acid over Mo1V0.25Nb0.12Pd0.0005Ox. J. Catal. 2002, 205 (1), 16-31.

35. Eichelbaum, M.; Glaum, R.; Havecker, M.; Wittich, K.; Heine, C.; Schwarz, H.; Dobner, C. K.; Welker-Nieuwoudt, C.; Trunschke, A.; Schlogl, R., Towards Physical Descriptors of Active and Selective Catalysts for the Oxidation of $n$ Butane to Maleic Anhydride. Chemcatchem 2013, 5 (8), 2318-2329. 
36. Kube, P.; Frank, B.; Wrabetz, S.; Kröhnert, J.; Hävecker, M.; Velasco-Vélez, J.; Noack, J.; Schlögl, R.; Trunschke, A., Functional Analysis of Catalysts for Lower Alkane Oxidation. ChemCatChem 2017, 9 (4), 573-585.

37. Bao, X.; Barth, J. V.; Lehmpfuhl, G.; Schuster, R.; Uchida, Y.; Schlögl, R.; Ertl, G., Oxygen-induced restructuring of Ag(111). Surf. Sci. 1993, 284 (1-2), 14-22.

38. Froment, G. F.; Bischoff, K. B.; De Wilde, J., Chemical Reactor Analysis and Design. 3rd Edition ed.; John Wiley \& Sons: 2011.

39. Van Parijs, I. A.; Froment, G. F., Kinetics of Hydrodesulfurization on a CoMo/YAl2O3 Catalyst. 1. Kinetics of the Hydrogenolysis of Thiophene. Industrial and Engineering Chemistry Product Research and Development 1986, 25 (3), 431436.

40. Sanfiz, A. C.; Hansen, T. W.; Teschner, D.; Schnörch, P.; Girgsdies, F.; Trunschke, A.; Schlögl, R.; Looi, M. H.; Hamid, S. B. A., Dynamics of the MoVTeNb oxide M1 phase in propane oxidation. Journal of Physical Chemistry C 2010, 114 (4), 1912-1921.

41. Trunschke, A.; Noack, J.; Trojanov, S.; Girgsdies, F.; Lunkenbein, T.; Pfeifer, V.; Havecker, M.; Kube, P.; Sprung, C.; Rosowski, F.; Schlogl, R., The Impact of the Bulk Structure on Surface Dynamics of Complex Mo-V-based Oxide Catalysts. Acs Catalysis 2017, 7 (4), 3061-3071.

42. Glemser, O.; Haeseler, R. V.; Müller, A., Gasförmige Hydroxide. VII. über gasförmiges $\mathrm{TeO}(\mathrm{OH}) 2.1964,329(1), 51-55$.

43. Glemser, O.; v. Haeseler, R., Über gasförmiges $\mathrm{TeO}(\mathrm{OH}) 2$ - Gasförmige Hydroxyde III. Die Naturwissenschaften 1960, 47 (20), 467-468.

44. van Parijs, I.; Froment, G. F.; Delmon, B., Kinetic Models for the Hydrogenolysis of Thiophene. A Comparison of Hougen-Watson Models with Fixed and Interconverting Sites for Hydrogenolysis and Hydrogenation. Bull. Soc. Chim. Belg. 1984, 93 (8-9), 823-830.

45. Van Parijs, I. A.; Froment, G. F., Kinetic modelling of catalytic reactions with a varying concentration of active sites. An analysis of the remote control model for HDS-catalysts. Applied Catalysis 1986, 21 (2), 273-285.

46. Van Parijs, I. A.; Hosten, L. H.; Froment, G. F., Kinetics of the Hydrodesulfurization on a CoMo/y-Al2O3 Catalyst. 2. Kinetics of the Hydrogenolysis of Benzothiophene. Industrial and Engineering Chemistry Product Research and Development 1986, 25 (3), 437-443.

47. Pille, R. C.; Yu, C. y.; Froment, G. F., Kinetic study of the hydrogen sulfide effect in the conversion of thiophene on supported CoMo catalysts. J. Mol. Catal. 1994, 94 (3), 369-387.

48. Trunschke, A.; Bellini, G.; Boniface, M.; Carey, S. J.; Dong, J.; Erdem, E.; Foppa, L.; Frandsen, W.; Geske, M.; Ghiringhelli, L. M.; Girgsdies, F.; Hanna, R.; Hashagen, M.; Hävecker, M.; Huff, G.; Knop-Gericke, A.; Koch, G.; Kraus, P.; Kröhnert, J.; Kube, P.; Lohr, S.; Lunkenbein, T.; Masliuk, L.; Naumann d'Alnoncourt, R.; Omojola, T.; Pratsch, C.; Richter, S.; Rohner, C.; Rosowski, F.; Rüther, F.; Scheffler, M.; Schlögl, R.; Tarasov, A.; Teschner, D.; Timpe, O.; Trunschke, P.; Wang, Y.; Wrabetz, S., Towards Experimental Handbooks in Catalysis. Top. Catal. 2020.

49. Trunschke, A.; Noack, J.; Trojanov, S.; Girgsdies, F.; Lunkenbein, T.; Pfeifer, V.; Hävecker, M.; Kube, P.; Sprung, C.; Rosowski, F.; Schlögl, R., The Impact of the Bulk Structure on Surface Dynamics of Complex Mo-V-based Oxide Catalysts. ACS Catalysis 2017, 7 (4), 3061-3071. 
50. Fushimi, R.; Shekhtman, S. O.; Gaffney, A.; Han, S.; Yablonsky, G. S.; Gleaves, J. T., TAP Vacuum Pulse-Response and Normal-Pressure Studies of Propane Oxidation over MoVTeNb Oxide Catalysts. Industrial \& Engineering Chemistry Research 2005, 44 (16), 6310-6319.

51. Yablonskii, G. S.; Bykov, V. I.; Elokhin, V. I.; Gorban, A. N., Kinetic models of catalytic reactions. Elsevier Science Publishers: The Netherlands, 1991; Vol. 32.

52. Celaya Sanfiz, A.; Hansen, T. W.; Girgsdies, F.; Timpe, O.; Rödel, E.; Ressler, T.; Trunschke, A.; Schlögl, R., Preparation of Phase-Pure M1 MoVTeNb Oxide Catalysts by Hydrothermal Synthesis-Influence of Reaction Parameters on Structure and Morphology. Top. Catal. 2008, 50 (1), 19.

53. Córdoba, A.; Bascón, M. L.; Lemos, M. C., Multiplicity in Adsorption on Heterogeneous Surfaces. Langmuir 1997, 13 (5), 1168-1172. 